\title{
Nas entrelinhas da hierarquia e disciplina: os alicerces da profissão naval*
}

\author{
Between the lines of hierarchy and discipline: the foundations of naval profession
}

\section{Elizabeth Espindola Halpern*}

Resumo: O exame dos conceitos de hierarquia e disciplina foi realizado por meio de uma análise sócio-histórica de modo a compreender as circunstâncias de sua produção e seus efeitos. Esses preceitos foram produzidos a partir de uma lógica que começou a prevalecer em favor da criação de um militar-padrão para compor os exércitos permanentes, oriundos da racionalidade científica, cujo paradigma mecânico tornou-se o padrão de inteligibilidade para a compreensão do mundo. A profissionalização do militar, em substituição ao recrutamento à força, foi impregnada por esta racionalidade, ajudando a construir as fronteiras entre os militares obedientes e os desviantes, reforçando a existência de processos de exclusão e estigmatização. Este artigo apresenta parte dos resultados da pesquisa que resultou na Tese de Doutorado do curso do Programa de Pós-Graduação do Instituto de Psiquiatria da Universidade Federal do Rio de Janeiro apresentando as narrativas dos militares que são pacientes alcoolistas de um ambulatório da Marinha do Brasil.

Palavras-chave: hierarquia; disciplina; militares.

Abstract: The examination of the concepts of hierarchy and discipline was conducted through a socio-historical analysis in order to understand the circumstances of its production and their effects. These precepts were produced from a logic that began to

\footnotetext{
- Este artigo apresenta parte dos resultados da Tese de Doutorado do curso do Programa de Pós-Graduação do Instituto de Psiquiatria da Universidade Federal do Rio de Janeiro.

" "Doutora em Saúde Mental pelo Instituto de Psiquiatria da Universidade Federal do Rio de Janeiro, Mestre em Saúde Coletiva pelo Instituto de Medicina Social da Universidade do Estado do Rio de Janeiro, Psicóloga e Capitão-de-Fragata da Marinha do Brasil. E-mail: espindolahalpern@yahoo.com.br
} 
prevail in favor of creating a military standard to compose the standing armies, originating from a scientific rationality, whose mechanical paradigm became the standard of intelligibility for understanding the world. The professionalization of the military, replacing the impressment, was impregnated by this rationality, helping to build the boundaries between the obedient military and the deviant, reinforcing the existence of processes of exclusion and stigmatization. This article presents some results of the research that resulted in the Doctoral Thesis of the course of the Post-Graduate Institute of Psychiatry, Federal University of Rio de Janeiro, presenting the narratives on military who are alcoholic patients in an outpatient clinic of Brazilian Navy.

Keywords: hierarchy; discipline; military personnel.

\section{Introdução}

A realização de uma análise sócio-histórica viabilizou a compreensão do papel da hierarquia e da disciplina na construção de uma distinção entre os "marinheiros dóceis" e "marinheiros marginais", tendo em vista que esses preceitos têm uma trajetória histórica e uma origem e bases sociais. Estudos com pacientes militares alcoólicos em tratamento em um ambulatório naval identificaram que um julgamento moral participa na identificação de erros no trabalho, empregando-se medidas de punição e de exclusão correspondentes (HALPERN, LEITE, 20IIa; 20IIb; 20I2; 20I3a; 20I3b; 20I4a; 20I4b; 20I4c; 20I4d; 20I4e). Esse assunto será desenvolvido adiante.

Acredita-se que a hierarquia e a disciplina sejam decorrências da racionalidade científica moderna, regidas pelo paradigma mecânico, pautado na física newtoniana. Em termos globais, esta racionalidade esteve presente ao longo de quatro séculos, do século XVI ao XIX, mormente com o surgimento da cosmovisão embasada no antropocentrismo humanista, em substituição ao teocentrismo medieval.

Com efeito, intensas transformações sacudiram os dogmas religiosos e abalaram os seus domínios, colocando em cena atores sociais que, de figurantes, tornaram-se protagonistas, orquestrando a economia capitalista mercantil, apoiada pelas inovações científicas. Profundas alterações ocorreram, não apenas de forma objetiva, com o estímulo à exploração das terras longínquas, como também de maneira subjetiva, afetando os 
modos de ser, de pensar e de agir dos indivíduos, até a consolidação do mundo industrial no século XVIII.

$\mathrm{Na}$ verdade, desde o século XVI, o Ocidente tornou-se palco de significativas transformações nas relações de poder, sociedade, política, economia e no próprio modo de ser dos indivíduos, afetando o saber e as práticas sociais, que se atualizaram em diversas instituições. Impregnadas por essa racionalidade, determinadas organizações, tais como as militares, se imbuíram de ordenar as relações sociais e de construir sujeitos segundo uma ordem racional moralizante, disciplinária, em consonância com o capitalismo vigente. $\mathrm{O}$ paradigma mecânico serviu de lente para divisar um novo mundo que se descortinava à experiência, moldando as palavras e as coisas. Os indivíduos e seus relacionamentos ganharam inteligibilidade por meio da concepção do mundo visto como máquina, tornando-se objeto das ciências comprometidas com a lógica da produtividade (LUZ, I988).

Imersas na cosmovisão mecanicista, as instituições militares foram sendo construídas, assim como seus integrantes, atuando como componentes articulados a serviço do Estado, imbuídos dos valores, deveres, preceitos e ética militares. Apesar de o homem ter protagonizado tal revolução, nos costumes e nas ideias, ao mesmo tempo, ele foi sendo reduzido a uma peça da mecânica industrial, fabril e militar. A hierarquia e a disciplina tornaram-se dois quesitos basilares para a composição do poder militar na forma como foi organizado para servir ao Estado, alicerçando as fundações da profissão militar naval. Incorporadas de forma ampla no discurso e práticas sociais a partir do Renascimento, essas noções impregnaram os princípios que passaram a reger o sistema militar.

Fundamentando-se nos preceitos de hierarquia e disciplina, Mauricio de Nassau foi considerado o progenitor do moderno corpo de oficiais europeu, responsável pela introdução da ética básica da profissão que previa a obediência incondicional, lealdade e serviço ao Estado. Durante o período em que permaneceu em solo brasileiro, Nassau também influenciou a identidade das forças militares. Alinhado aos ideais humanistas, seus métodos converteram-se nos padrões normativos para todos os exércitos europeus, revolucionando a mentalidade sobre as funções dos soldados. A edificação da essência do militarismo precisou trilhar um longo caminho até determinar o modelo vigente (ROTHENBERG, 200I).

No Brasil, em particular, a hierarquia e a disciplina serviram de cimento para dar solidez às bases das Forças Armadas brasileiras e para estreitar os laços de compromisso com seus membros. Graças a este alicerce, a Marinha, Exército e Aeronáutica continuam a 
se organizar para a defesa da Pátria e o cumprimento da lei e da ordem, conforme preconizado pelo texto constitucional de I988 (BRASIL, I988). "A ordem, que garante a estrutura, e a disciplina, que afigura as relações sociais. Como os dois são aspectos do mesmo jogo, são dependentes um do outro" (LUZ, I979, p. 35-36). Esses preceitos também foram contemplados no Estatuto dos Militares (BRASIL, I980), documento que estabelece a situação, obrigações, deveres, direitos e prerrogativas dos militares, bem como os valores, princípios éticos e deveres militares da profissão militar.

Uma leitura mais atenta ao que está redigido convida à reflexão sobre o que realmente se espera de um militar, sem naturalizar os seus conteúdos. Por exemplo, o patriotismo implica na vontade inabalável de cumprir o dever militar e no solene juramento de fidelidade à pátria, até com o sacrifício da própria vida. A hierarquia demanda a promoção do espírito de acatamento à sequência de autoridade; a disciplina requer a rigorosa observância das leis, regulamentos, normas e disposições que fundamentam o organismo militar, visando o perfeito cumprimento do dever por parte de cada componente/membro. Como partes do organismo institucional, os militares formam uma categoria "especial" de servidores da pátria, inteiramente devotados às Forças Armadas. Logo, os militares são partes de um corpo institucional, visão que prevalece sobre o seu corpo individual. Tal forma de se referir aos seus integrantes sugere que eles são peças de uma engrenagem, com uma função biomecânica, predominando uma maneira impessoal de se referir a eles, tornando mais fácil o acatamento às ordens.

De fato, as formas discursivas contidas nesse regulamento estão impregnadas pela cosmovisão regida pela lógica mecanicista newtoniana. Com efeito, as normas e os regulamentos militares foram afetados pelos valores emanados dos ideais do Iluminismo, como pode ser atestado no conteúdo e na redação do Estatuto, sem que se proceda a um questionamento, sobretudo por parte daqueles que fazem parte de seu contingente, que tendem a naturalizá-lo.

No caso da disciplina, Foucault (1979) entende que ela seria um fator determinante para o funcionamento de todas as relações entre militares, dando primazia às normas de conduta coletiva, mediante a anulação das expressões individuais. Embora a disciplina já estivesse presente na Antiguidade, ela teria se tornado uma técnica de gerir homens no decorrer do século XVIII, uma arte de distribuí-los no espaço, extraindo deles a sua máxima utilidade. O soldado passou a ter maior valor no tabuleiro do combate, sobretudo porque ele tornou-se mais habilidoso quando aprendeu a manejar o fuzil, requerendo treinamento, perícia e mobilidade (FOUCAULT, 1975/2007; 1979). O seu corpo converteu-se 
em peça de uma máquina, distinta de massa disforme e aglomerada formada por indivíduos que compunham os exércitos no século XVII.

A disciplina fez com que os corpos se tornassem submissos para serem úteis, atuando sobre seus movimentos e gestos, impondo-lhes obrigações, limitações e proibições. O emprego de algumas técnicas evitariam os atos de violência, deserção e vadiagem, tais como a sua colocação em quartéis e o seu quadriculamento, estabelecendo o lugar de cada um, com funcionalidade, criando espaços úteis. Nesse contexto, um novo jogo articulado entrou em cena: “A unidade - regimento, batalhão, seção, mais tarde 'divisão' - torna-se uma espécie de máquina de peças múltiplas que se deslocam umas em relação às outras para chegar a uma configuração e obter um resultado específico" (FOUCAULT, 1975/2007, p. 138). A disciplina tornou-se uma forma privilegiada de poder e de dominação, submetendo os indivíduos à eterna pirâmide de olhares. "É assim que no exército aparecem sistemas de graus que vão, sem interrupção, do general chefe até o ínfimo soldado, como também os sistemas de inspeção, revistas, paradas, desfiles, etc., que permitem que cada indivíduo seja observado permanentemente" (FOUCAULT, 1979, p. I06).

As pesquisas de Leirner (1997) no Exército brasileiro conferem um peso maior ao papel da hierarquia nas organizações militares. Ela seria um princípio norteador da vida aquartelada e regulador de todas as condutas, servindo de base para que determinados aspectos sejam exteriorizados, incluindo as ordens, honras, continências, cerimonial, dentre outras manifestações. Na prática, a hierarquia não funcionaria como um sistema piramidal; prevaleceria um sistema de posições por meio do qual “(...) a hierarquia é capaz tanto de abarcar o 'todo', como um princípio geral, quanto o indivíduo, como segmentação que determina o lugar pessoal que se deve ocupar" (LEIRNER, I997, p. II6). Ela segmentaria o grupo segundo a patente ou graduação, estabelecendo seus lugares na cadeia de comando. Somado a isso, os círculos hierárquicos também promoveriam a segmentação na medida em que garantiriam a convivência de militares da mesma categoria em espaços designados: salas, refeitórios, banheiros, dentre outros. As fronteiras que enquadram os sujeitos na pirâmide organizacional são estabelecidas por meio de um sistema de classificação, evidenciando que a segmentação se faz de pessoa a pessoa, dando ênfase às diferenças individuais, levando em conta o mérito e antiguidade.

A questão levantada por Da Matta (1983) sobre "você sabe com quem está falando?", que evidencia o valor do particular e do hierarquizado na sociedade brasileira, foi ponderada por Leirner (1997) ao dizer que, no âmbito militar, sempre se sabe com quem está se falando, pois o status de cada um estaria evidente. No entanto, retomando o ponto de vista 
de Da Matta, apesar dos uniformes e das insígnias revelarem a posição do militar na cadeia de comando, ainda assim é necessário esclarecer qual vem a ser a sua posição na hierarquia social, justamente porque ela não se esclarece nas divisas exibidas nas fardas ou nas funções desempenhadas. Ao contrário, nunca se pode ter certeza sobre "com quem está se falando", mesmo nas Forças Armadas.

Nas entrelinhas da caserna existem outros elementos que não são expostos, porém, são ostensivos, tais como as razões que levam os militares a terem ou não prestígio. Essas informações circulam nos corredores, nas conversas furtivas, especialmente quando os assuntos denigrem a imagem de algum militar. No dia a dia, elas acabam ganhando primazia sobre o brilho dos uniformes, suficientemente fortes para provocar baques em uma carreira, demonstrando que a hierarquia não tem o poder de reger as relações no interior da vida militar como se pensa.

As medalhas e o dourado das platinas que reluzem no topo da pirâmide podem corresponder ao mérito, tempo de serviço ou antiguidade, mas nem sempre essa é uma equação constante. Na prática, não é possível divisar o seu valor baseando-se naquilo que é visível: um militar de alta patente pode estar naquela posição como resultado de fatores que nada têm a ver com o merecimento, mas pelos efeitos de políticas, de afetos e desafetos. Isso vale para a situação inversa: nem sempre um militar menos graduado tem pouco valor. Acredita-se que existam aspectos relacionais que permeiam a aparente rigidez da hierarquia e a influência da disciplina. Portanto, Leirner (1997) tem razão ao dizer que o mérito é decidido a partir de uma complexa rede de relações pessoais, quebrando a linha rígida instituída pela cadeia de comando por patentes.

Mais que ser um princípio piramidal estático, a hierarquia é um princípio segmentador que pode ser usado de duas formas: seja para assegurar uma ordem organizada de precedências, por meio da qual uns vêm antes que outros, levando em consideração as diferenças individuais, funcionando como uma "fila indiana", metáfora empregada por Abreu (1998); seja para rompê-la, ou melhor, para "furar a fila". Justamente por causa das diferenças individuais, certos mecanismos internos nas organizações militares se curvam às estratégias de inclusão e exclusão que, sem dúvida, não são neutras, colocando a hierarquia e a disciplina a serviço de múltiplos interesses. Assim sendo, o "ínfimo" soldado pode ter mais poder do que revelam as suas magras divisas: as aparências enganam! Portanto, o entendimento que Leirner (1997) e Abreu (1998) têm sobre a hierarquia como princípio capaz de organizar as relações entre os militares para além da 
cadeia de comando precisaria ser expandido, tendo em vista que, a hierarquia e a disciplina são instrumentos para o exercício do poder e da dominação.

A cadeia de comando, que supõe uma relação assimétrica na qual existiria um indivíduo que manda e outro que obedece, pode ser invertida ou subvertida no cotidiano militar. A hierarquia e a disciplina não garantem que ela seja respeitada; não é incomum a ocorrência do bypass, ou seja, de desvios na sequência da linha de comando. Isso pode ocorrer por vários motivos, por distração ou descuido, ou para privilegiar ou desmerecer alguém. Nessa última situação, um militar pode deixar de ser promovido apesar do seu merecimento ou antiguidade por ter sido "bypassado" por outro mais moderno, causando embaraços, geralmente para atender aos critérios de preferências/repulsas.

Outro exemplo que ilustra a quebra ou desvio refere-se ao trâmite de algum documento que poderá "seguir o canal" ou ficar estagnado em alguma "gaveta", dependendo do assunto em pauta e dos sujeitos envolvidos, tendo em vista os interesses em jogo. Interessante notar que um apelo ao pé do ouvido de um subalterno que serve no gabinete de um Diretor pode ter mais influência no destino desse documento do que as "platinas" do superior hierárquico. A hierarquia e a disciplina são alicerces mais flexíveis do que se pode imaginar, podendo ser afrouxados ou tensionados em função dos interesses vigentes. Por isso, retorquindo o que Abreu (1998) fala sobre a cadeia de comando: "o que está em 'jogo' são ordens de um lado e obediência de outro”, acredita-se que o que esteja em pauta seja o desejo (volátil) sobre a aplicação do poder, vontade que pode se articular nos bastidores institucionais de forma inconstante e errática. Logo, não se trata de um processo decisório que cumpre etapas previsíveis, seguindo um roteiro estável; na realidade, ele é afetado por interesses variados, ao bel prazer de associações e disjunções.

\section{O poder disciplinador: "marinheiros dóceis" e "marinheiros marginais"}

A proposição da distinção entre "marinheiros dóceis" e "marinheiros marginais" decorre dos efeitos de uma lógica que passou a prevalecer em favor da criação de um militar-padrão. Vale esclarecer que os militares na Marinha brasileira que desviam do modelo idealizado, convertem-se em "marinheiros marginais", ao passo que aqueles que se enquadram nos parâmetros estabelecidos, seriam os "marinheiros dóceis" (HALPERN, LEITE, 2OIIb).

O emergente Estado Moderno, tido como aquele que foi sendo constituído no final do século XV com o progressivo desenvolvimento institucional até culminar com a 
ascensão do absolutismo e do capitalismo, demandava a constituição de um exército permanente para assegurar a unidade nacional. Para tal, era imperativo que houvesse, por parte da população, a assimilação da ideia da obrigação militar, acatamento às leis e pagamento de impostos (PALMER, 200I). Para guarnecê-lo, tornou-se necessário um tipo de combatente - o soldado-cidadão - submetido à hierarquia e disciplina, pronto para obedecer e comandar e, sobretudo, disposto a defender o Estado com o sacrifício da própria vida. Portanto, os Estados fizeram as guerras, e as guerras fizeram os Estados, já que elas ajudaram os governos a construírem suas bases institucionais (TILLY, I987).

O protótipo do soldado-cidadão deveria ser compatível com o modelo de "marinheiro dócil”, obediente, ajustado ao perfil profissiográfico segundo as exigências do Estadonação. "É dócil um corpo que pode ser submetido, que pode ser utilizado, que pode ser transformado e aperfeiçoado" (FOUCAULT, I975/2007, p. II8). Os corpos se "adoçam" quando úteis, produtivos e submissos; afáveis, curvam-se aos regulamentos, ideologias e obrigações: operações viabilizadas pela disciplina. Em contraposição, o sujeito que não fosse suficientemente "dócil" para se adequar aos pressupostos desse modelo seria marginalizado, submetido às sanções, geralmente aos castigos corporais que, por sinal, faziam parte da rotina diária. O número de chibatadas dirigidas à "escória" variava conforme a infração: nos casos de embriaguez, eram 25 chibatadas por dia, aplicadas por Portaria, encenadas em cerimônia solene, dramatizando a sua imposição (GREENHALGH, 1998).

No Brasil, o castigo era aplicado conforme as disposições descritas nos Artigos de Guerra (BRASIL, I84I), segundo a "praxe" (costume) aprendida no cotidiano das embarcações, com objetivos corretivos, pedagógicos, exemplares e disciplinares. Apesar da existência dos regulamentos e dos códigos penal e disciplinar, a interpretação de quem os aplicava, desde os tempos da Marinha de Guerra, definia o que valia ou não na rotina do navio. A guarnição era consciente dessa realidade; por isso, era fundamental consolidar uma experiência a bordo que trouxesse um aprendizado sobre como se conduzir, como lidar com a discrepância entre o que constava nas normas escritas e nas ordens verbalizadas pelo Comandante, de modo a evitar o comportamento que comprometesse o Comando do navio. Arbitrado pelo tribunal de convés, a aplicação do castigo rápido e objetivo permitia que o faltoso permanecesse na embarcação, sem reduzir seu contingente já escasso (NASCIMENTO, 200I). Dessa forma, o poder disciplinador viabilizaria o permanente enquadramento (ou reenquadramento) dos "marinheiros marginais" para manter a ordem. "As disciplinas, organizando as 'celas', os 'lugares' e as 'fileiras' criam 
espaços complexos, ao mesmo tempo, arquiteturais, funcionais e hierárquicos" (FOUCAULT, 1975/2007, p. I26).

\section{Do recrutamento forçado à profissionalização militar}

Em busca do modelo exemplar de militar para guarnecer os quartéis e as fileiras para os combates, percorreu-se uma trajetória marcada por contrassensos, violência e sofrimento. As experiências nefastas na caserna e nas batalhas geravam ojeriza na população ao recrutamento. No Brasil e na Europa, a conscrição era temida e evitada. Na prática, o ingresso de voluntários requereu uma manobra de convencimento difícil de ser vitoriosa, porquanto poucos estavam convictos da necessidade e importância de lutarem por uma "pátria", um conceito que foi produzido com o advento do Renascimento, no século XVI. Há que se esclarecer que o Brasil como país ainda não existia até então. Ademais, somente se pode falar em uma Marinha brasileira no século XIX. Assim, o enfardamento se desenrolou de forma progressiva, acompanhando a construção da nação e da Marinha brasileiras:

Decidiu-se por nomear de enfardamento o processo de assimilação dos valores e preceitos militares ao ponto de conformarem uma "mentalidade" ou um "espírito", capaz de fazer do indivíduo um membro do corpo militar e servidor da pátria. A trajetória do enfardamento se desenrola de duas formas: por um lado, ela ocorreu ao longo da história, desde o audaz marujo que enfrentava os mares desconhecidos em busca de tesouros que se converteu em um integrante fardado da pirâmide hierárquica, especializado no manuseio de equipamentos de navegação sofisticados. Por outro lado, o enfardamento se atualiza diariamente no seio institucional por meio de diversas estratégias (HALPERN, LEITE, 20I4d, p. I75).

A guerra e a pátria foram dois conceitos historicamente construídos que serviram de ferramenta para assegurar a formação e o desenvolvimento dos Estados nacionais, sendo um pretexto para a montagem dos exércitos nacionais. A nova concepção de patriotismo, "ideia-argamassa" que deu solidez ao exército nacional, conferiu um elo transcendental entre a pátria e seus combatentes, como uma obrigação moral, um dever universal, estimulando o povo a demonstrar um amor incondicional a ela, oferecendo a própria vida em sacrifício. No Brasil, apesar do processo de criação do Estado nacional ter se 
consolidado na forma de um país a partir de I850, não havia a perspectiva de ser uma nação investida de um sentimento de identidade. A imagem de pátria demorou a fazer parte do horizonte mental dos brasileiros uma vez que eles não participaram da construção da imagem nacional. A nação brasileira ainda era uma ficção, permanecendo desse jeito nas primeiras décadas da República (CARVALHO, 1995). Portanto, fez-se necessária a aplicação de operações na mentalidade do povo para que o recrutamento forçado fosse substituído pelo ingresso eletivo.

O recolhimento compulsório no Brasil imperial era feito durante a noite por patrulhas militares ou da polícia que aprisionavam os mais variados malfeitores: vadios, ladrões, desordeiros e alcoólatras, fazendo deles marinheiros ou soldados (GREENHALGH, 1998). A conscrição em solo brasileiro caracterizou-se pela economia moral do recrutamento, recrutando os que não se encontravam sob o abrigo das redes sociais de proteção. As "regras não escritas" de seleção prevaleciam, tendo como alvo os indivíduos "improdutivos" da sociedade, por terem um comportamento, ou inaceitável, ou a ser corrigido. Esse processo se fazia de forma altamente arbitrária, imprevisível e errática, à mercê das liturgias, por meio da participação não remunerada e voluntária dos notáveis locais, de acordo com a lógica da dádiva, firmada por uma troca silenciosa de favores, edificadas por pactos e barganhas. Empregavam-se mecanismos de identificação dos comportamentos "desviantes" para a captação dos recrutas para distinguir os "maus filhos" ou "mal casados". A administração honorária com ordens de privilégio sinalizava a existência de uma complexa trama de negociações, resistências e compromissos (MENDES, I998; 2004).

Izecksohn (2004) confirma a existência de um intricado sistema de isenções legais que impediam o alistamento, obrigando o pequeno Exército imperial a recrutar aqueles que não contavam com a proteção de pessoas influentes que os isentassem daquela obrigação militar, geralmente os desocupados, potenciais criminosos e desempregados, enfim, os socialmente indesejáveis. Em I865, apesar das 2.500 adesões para comporem os batalhões dos voluntários da pátria ${ }^{\mathrm{I}}$, a tônica era a da fuga, escondendo-se nas matas, no matrimônio ou realizando a automutilação, quando não havia um protetor para livrar o indivíduo desse compromisso "patriótico". Eles eram considerados como "fezes da população" (ARIAS NETO, 200I); tomava-se como certeza a existência de pessoas da pior espécie que já teriam sido recrutadas nesse estado, passíveis de punições. O juízo antecipado sobre os conscritos

\footnotetext{
${ }^{\text {I }}$ Vale esclarecer que, por ocasião da Guerra do Paraguai, os Voluntários da Pátria eram unidades militares recrutadas em I865, pelo Império do Brasil, para reforçar o efetivo das tropas brasileiras, sendo parte de uma campanha do governo para o recrutamento que, inicialmente ocorreu de forma voluntária e, adiante, forçada.
} 
era sacramentado pela aplicação dos rígidos regulamentos, estabelecendo as linhas demarcatórias entre os papéis e espaços sociais a serem ocupados por Oficiais e subalternos, legitimando práticas punitivas. Os conscritos ou "feras", recrutados à força, precisavam ser dominados pelo inclemente uso da chibata (MARTINS, 2005).

$\mathrm{Na}$ virada do século XIX, buscou-se reverter essa imagem negativa, conquanto as "feras" precisavam ser substituídas pela profissionalização do militar para lidar com a sofisticação tecnológica dos navios e dos armamentos. A noção de que a proficiência somente seria adquirida de forma prática e aleatória no convés do navio foi substituída pelas concepções profissionais que se desenvolveram com o iluminismo militar alemão que tinha como ênfase uma formação básica horizontal e nas ciências militares, com destaque na educação dos Oficiais pela experiência (DUARTE, 2008). Com efeito, objetivava-se redefinir o perfil do militar, fazendo-se necessário o recrutamento não mais de "feras", mas de técnicos especializados.

A questão da profissionalização do militar fez parte de um intenso debate que se desenrolou no século XIX. Segundo Huntington (1997), havia uma discussão em solo norteamericano a respeito da vocação do militar, organizando-se nas vertentes profissionalista hamiltoniana e tecnicista jeffersoniana. O profissionalismo hamiltoniano considerava que o bom soldado conheceria as obrigações do cargo, sendo central a instrução nos fundamentos da arte da guerra, concepção que impulsionou as áreas de formação, de pessoal e de organização militares. Por considerar a guerra inevitável, ela defendia a manutenção de um corpo de Oficiais profissional concentrado nos preparativos militares, inclusive em tempos de paz. Em contraste, a corrente jeffersoniana entendia que o bom militar era um especialista com habilidade técnica. O pacifismo subjacente a ela se alinhava à opinião de que a guerra era uma alternativa obsoleta e dispendiosa, incompatível com as metas do liberalismo econômico. A concepção vitoriosa apoiava a profissionalização e a criação de instituições permanentes, introduzindo os princípios de hierarquia e disciplina, bem como a glorificação de valores tais como a subordinação, lealdade e cumprimento do dever.

Todavia, a chibata continuou a ser usada em pleno século XX. Aos poucos, mediante sua profissionalização, os processos de "domesticação" dos militares passaram a prescindir dos castigos corporais. Embora eles não sejam mais desferidos sobre o corpo, as punições dos tempos atuais também machucam, ferindo a sua subjetividade. Acredita-se que diversas expressões de violência sejam continuamente dirigidas aos "corpos marginalizados" pelo poder disciplinador naval, desde a gênese da Marinha do Brasil, 
selando o destino sombrio de muitos militares, sobretudo pelo emprego ambíguo dos regulamentos.

\section{Processos de exclusão e de estigmatização}

Para que se proceda ao exame dos processos de exclusão e de estigmatização no interior das organizações militares, em particular da Marinha brasileira, acredita-se que seja relevante compreender que os documentos normativos que regem o funcionamento e organização da Marinha brasileira, assim como os papéis de seus militares, foram socialmente e historicamente produzidos.

Inspirada nos ideais do iluminismo, a Marinha brasileira criou documentos normativos para reger o funcionamento da organização e os papéis dos militares. Destacam-se o Estatuto dos Militares (BRASIL, 1980) e a Ordenança Geral para o Serviço da Armada (OGSA) (BRASIL, I987). O Estatuto, como já foi explorado, serve de baliza para definir o modelo de comportamento esperado, estabelecendo quais os valores e ética fundamentais ao militar, entre outras coisas. A Ordenança, por sua vez, estipula como se deve alcançar a correta condução das atividades diárias nas unidades militares, visando o bom desempenho profissional de modo uniforme e eficiente. Adicionalmente, ela tem por objetivo a preservação de valores que se cristalizaram nas tradições navais, viabilizando a manutenção dos usos, costumes e linguagem naval. A OGSA exorta os militares a zelarem pelo funcionamento da organização naval, a nível material e pessoal, mantendo um padrão exemplar de funcionamento, em constante supervisão. Desse modo, espera-se que todos assumam inteira responsabilidade pelo desempenho no cargo, assim como executem uma ordem de forma perfeita. Considera-se que todos são individualmente responsáveis, dentro de sua esfera de ação, seja por negligência, imprevidência, fraqueza ou falta de energia no cumprimento de deveres e no desempenho de suas atribuições.

O constante emprego do jogo do olhar (FOUCAULT, 1975/2007) dá vida à OGSA, aciona a vigilância hierárquica, desmascarando, por meio da aplicação de técnicas coercitivas, aqueles que não respondem às exigências laborais. A amplitude do que se espera de um militar acaba por tornar hercúlea a tarefa de corresponder com o que se encontra preconizado, aumentando as chances dele incorrer em erros. Com efeito, processos de exclusão e de estigmatização são acionados pelo grupo dos estabelecidos (established) em direção aos estranhos (outsiders), como propõem Elias e Scotson (2000). Os primeiros ocupam posições de prestígio e poder, reconhecidos como a "boa sociedade" 
("marinheiros-dóceis"), enquanto que os outsiders ("marinheiros-marginais"), com menor coesão, seriam excluídos desse grupo, recebendo um rótulo de inferioridade. O grupo dos "marinheiros-dóceis" (established) tenderia a ser representado pelos Oficiais, um segmento localizado no topo da pirâmide hierárquica; os "marinheiros-marginais" estariam associados às Praças, a base da cadeia de comando militar, constituída por Suboficiais, Sargentos, Cabos, Marinheiros e Soldados (HALPERN, LEITE, 20IIb). O grupo dos Oficiais ainda polariza a imagem idealizada e cultivada dos tempos que antecederam a República, ostentando uma etiqueta e tradições navais como se fossem seculares, quando, na verdade, o processo de sua profissionalização teve início recente.

O uniforme em desalinho ainda pode punir o militar brasileiro segundo o Regulamento Disciplinar para a Marinha $\left(\mathrm{RDM}^{2}\right)$ (BRASIL, I983). Determinados regulamentos, como o RDM, ainda guardam resquícios do espírito do Regimento Provisional da Armada (aprovado em I796) e seus Artigos de Guerra (aprovados em I80o), inspirados no Código de 1763 do Conde de Lippe (SCHAUMBURG-LIPPE, I794), considerado bárbaro, que foi a base da legislação militar portuguesa e brasileira. $\mathrm{Na}$ atualidade, o conteúdo do RDM se pauta na visão corrente sobre a falha humana relacionada à insuficiência, como se existisse um comportamento correto a ser adotado (DEJOURS, 2005). Subjacente a esta lógica, caberia um julgamento moral ao identificar o "componente patológico" da conduta, bem como a implantação de ações relacionadas com o controle, vigilância, instruções, regulamento, disciplina, sanção e/ou formação para corrigi-lo. Os seguintes itens exemplificam algumas das falhas tidas como contravenções disciplinares, conforme artigo $7^{\circ}$ do RDM (BRASIL, I983): "portar-se sem compostura em lugar público" (item 34); "contrair dívidas ou assumir compromissos superiores às suas possibilidades, comprometendo o bom nome da classe" (item 36); "estar fora do uniforme determinado ou tê-lo em desalinho" (item 4I).

É fácil identificar uma falha no indivíduo à luz desse regulamento, seja um deslize nos seus modos de agir ou no uso dos uniformes, deixando evidente sua natural vulnerabilidade. Assim, vai surgindo uma demarcação entre o "normal" e o "desviante", o "aceito" e o "rejeitado", o "certo" e o "errado". No cotidiano laboral, este crivo acaba sendo aplicado, preferencialmente, às graduações hierarquicamente inferiores, mais suscetíveis ao RDM, embora esteja explícito no artigo $5^{\circ}$, capítulo III, sobre a esfera da ação disciplinar, que este regulamento se dirige a todos os militares indistintamente. Ao se

\footnotetext{
${ }^{2}$ Este Regulamento tem por propósito a especificação e a classificação das contravenções disciplinares e o estabelecimento das normas relativas à amplitude e à aplicação das penas disciplinares, à classificação do comportamento militar e à interposição de recursos contra essas penas.
} 
reconhecer erros no trabalho que podem ser interpretados como contravenções disciplinares, medidas de punição ou até de exclusão costumam ser empregadas. A esse respeito, Giuliani (2006b) analisa a (dis)função do Juiz Militar na aplicação da lei penal castrense para preservar os princípios basilares das Forças Armadas: hierarquia e disciplina. Segundo esclarece, um pseudotribunal estaria formado na vida militar capaz de influenciar a sessão de julgamento considerando que, na prática, como salienta Coutinho (200I), não existiria neutralidade no momento de julgar, já que “(...) o Juiz militar poderá estar infectado com a disciplina e hierarquia e não será capaz de proferir uma decisão isenta com amparo na lei ao caso concreto" (GIULIANI, 2006b, p. 7). A disciplina estabelece uma infrapenalidade, determinando uma forma específica de punir a partir de um modelo reduzido de tribunal, pois, “(...) na essência de todos os sistemas disciplinares, funciona um pequeno mecanismo penal" (FOUCAULT, 1975/2007, p. I49). O superior hierárquico estaria imbuído do sentimento de punir o inferior que estivesse "fora da ordem" (DOUGLAS, I966).

$\mathrm{Na}$ trajetória de construção do profissional militar, além de serem estabelecidas as condições para o exercício da profissão do militar naval, modelado para ser um soldadocidadão, nesse mesmo enquadre define-se, por oposição, o militar "marginal". Considerando que nas Forças Armadas os princípios da hierarquia e disciplina estabelecem a ordem e a convenção, eles também permitiriam (de)marcar o que é puro e padrão conforme o ponto de vista institucional a fim de homogeneizar a conduta de seus integrantes. Mediante o surgimento do "desviante" que não seguiu as ordens, ele poderá ser banido da organização com o ritual da Justiça Militar pelo Processo. De fato, a disciplina e hierarquia militares encontram-se no Processo Penal Militar, na sessão de julgamento, incluindo desde a disposição espacial e cerimônias, até as fardas e os símbolos. "O ritual da sessão de julgamento tem a função de (re)estruturar a ordem quebrada e purificar, a fim de manter a disciplina e hierarquia das Forças Armadas (trans)postas no seu ritual específico de julgar um inferior hierárquico" (GIULIANI, 2006a, p. I6I). Embasado na ideia de ordem e desordem, pureza e impureza, profano e sagrado (DOUGLAS, 1966), assim como no uso do ritual para (re)estabelecer estas distinções e papéis, o Processo Penal Militar serve para (de)marcar o que é "puro" daquilo o que é "sujo", expurgando o elemento "patogênico", "inoportuno", para evitar a "contaminação" do grupo (GIULIANI, 2006a). "O perigo é controlado por um ritual que precisamente a separa do seu velho status, a segrega por um tempo e, então publicamente declara seu 
ingresso no novo status" (DOUGLAS, I966, p. II9-I20). Se, por um lado, a desordem estraga o padrão, ao mesmo tempo, ela fornece os elementos para determinar o que faz parte dele.

Outros rituais são usados no cotidiano naval para sustentar a ordem e manter as vigas institucionais íntegras. O cerimonial descrito por Giuliani faz parte de um momento mais dramático e decisivo que determinará a exclusão/limpeza do indesejável/impuro da organização. Trata-se de um processo constante de arrumação, particularmente intensificado nas Forças Armadas pelo compromisso historicamente firmado e rotineiramente reiterado com a perfeição, procurando fornecer provas de uma conduta exemplar, pessoal e profissional. Castro (1993) aponta que a identidade militar estaria assentada em uma visão construída de excelência, erigida em contraste com a identidade do civil. Os militares seriam disciplinados e comprometidos com a pátria, ao passo que os "paisanos" geralmente seriam preguiçosos e individualistas, sugerindo que os primeiros seriam melhores do que os segundos. Mais do que haver uma demarcação que segmentaria os grupos dos militares e dos civis, os primeiros tornando-se os established e os segundos os outsiders (ELIAS, SCOTSON, 2000), existiria um padrão que se repetiria ao infinito no seio institucional, estabelecendo novas segmentações entre os próprios militares. Sobretudo, trata-se de uma mecânica que reforça e reedita a assimetria entre sujeitos e grupos, acentuando a suposição de que existem os "melhores" e os "piores". Nesse sentido, as normas e os regulamentos navais, assim como seus tribunais, ajudam a demarcar as fronteiras entre os militares "dóceis" e os "marginais", acentuando essas diferenças. Portanto, o "desviante" é desmascarado e submetido aos mecanismos de controle, enquadramento ou de exclusão.

\section{Alicerces navais: soldado-cidadão "devotado" versus "escória" recrutada à força}

Apesar de a busca por um militar "exemplar", paradoxalmente, as fundações da MB foram edificadas por indivíduos considerados como proscritos: "marinheiros marginais", formados pela "escória" dos séculos XVIII e XIX (McBETH, I977; COSTA, I995; MENDES, I998; NASCIMENTO, 200I), recrutada à força nas esquinas, nos becos e nas tavernas para ajudar a manter a cidade limpa e organizada:

A ascensão do nacionalismo militarista encerrava uma ironia para os soldados brasileiros. Ainda que designados para defender a honra nacional, muitas praças vinham da mal-afamada classe dos desprotegidos. Os recrutadores, a polícia e os juízes extraíam a maioria dos recrutados das 
fileiras dos vadios, ex-escravos, órfãos, criminosos, migrantes, trabalhadores sem qualificação e desempregados. A maioria dos voluntários se alistava para escapar da fome, do desabrigo, do desemprego e, às vezes, da escravidão (BEATTIE, 2004, p. 274).

Predominava um estigma negativo do recrutado, correspondendo ao estereótipo do sujeito de moralidade duvidosa, frequentador de prostíbulos, violento e alcoólatra (RODRIGUES, 2004). Ademais, os conscritos eram considerados como homens sem família, ainda que fossem casados, fazendo deles sujeitos perigosos, passíveis de serem recrutados para afastá-los das casas de famílias honradas (BEATTIE, 2004). Inclusive, o termo soldado, nos tempos do Brasil colonial, era um eufemismo indicativo do homem solteiro degredado (COATES, 200I; BEATTIE, 2004). As sofríveis condições de recrutamento e de vida no interior da organização militar sacramentaram sua má fama.

Somente em fins do século XIX e início do XX tornou-se desejável a substituição da "escória" recrutada à força pelo profissional militar "devotado", em sintonia com seu novo papel social. Para tal, uma imagem positiva de militar passou a ser cultivada que fosse condizente com os emergentes padrões materiais e comportamentais que determinaram o homo urbanus, resultado do processo civilizatório. Esperava-se construir as bases das Forças Armadas brasileiras com o suporte de um contingente supostamente hígido e produtivo, segundo o ethos do trabalho, à luz do sistema de valores e da redefinição política e identitária estabelecidos para atender os interesses políticos e econômicos do sistema republicano brasileiro.

Apesar da herança histórica contraditória que mistura nobreza e pobreza, tradições são permanentemente reeditadas nas solenidades, formaturas e desfiles, de modo a perpetuar a ilusão de uma ancestralidade ilustre. Em contraste, a realidade revela que grande parte dos militares da MB precisa se desdobrar para sustentar a família e saldar as dívidas, tentando se enquadrar nos moldes prescritos. Contudo, prevalece um perfil de militar que foi importado, constituído de preceitos e valores que foram relevantes séculos atrás.

Muitos integrantes da MB, em pleno século XXI, geralmente de origem humilde, são "marginais" de nascença, oriundos de famílias mal constituídas, de lares fragmentados e protagonistas de biografias retalhadas. Com horizontes e perspectivas estreitados, seus futuros são incertos, precisando remendar falhas ancestrais, lacunas históricas, socialmente e culturalmente determinadas. Vacilantes, percorrem uma trajetória que sorri aos privilegiados, aos bem-nascidos, que desafia o acesso dos mais "fracos", ou melhor, dos 
menos "equipados". Iniciam a senda em franca desvantagem: são duramente julgados e, inexoravelmente, empurrados para os "lixões". Tornam-se refugos humanos, sujeitos nãoadaptados ao sistema que o Estado-nação da modernidade acredita ter o direito de excluir (BAUMAN, 2005). Correspondem ao segmento dos estranhos, ou seja, daqueles que não se encaixam no mapa cognitivo, moral ou estético do mundo, afastando-se do ideal de pureza da pós-modernidade, que introduz "anormalidades" a partir de diferentes linhas divisórias que identificam e separam novos "alienígenas". "Sujeira” que será enfrentada por duas estratégias alternativas e complementares: antropofágicas, engolindo os estranhos para abafar as distinções e as diferenças; ou antropoêmicas, vomitando, banindo e excluindo os estranhos (BAUMAN, 1998).

$\mathrm{Na}$ verdade, os atributos esperados do militar padrão, que servem de filtro modelador, são fruto de uma construção social da realidade. No entanto, esses predicados tendem a ser naturalizados como se fizessem parte de modo intrínseco e compulsório de suas identidades profissionais. A "incapacidade" ao enquadramento não equivale à "falha" ou "patologia", mas a uma provável inadequação perante um modelo construído, comprometido com um paradigma que vem sendo progressivamente esvaziado de sentido e que não consegue corresponder à realidade. Enfim, “(...) esse 'outro' desviante talvez não deva ser socializado, reabilitado ou curado para ficar igual a 'nós'” (YOUNG, 2002, p. 2I).

\section{Considerações finais}

Nessa oportunidade, cabe refletir se os parâmetros de outrora, que requeriam um militar disciplinado para dar a vida pela pátria, ainda devem prevalecer na atualidade. $\mathrm{Na}$ verdade, a própria concepção de guerra que motivou a formação dos exércitos permanentes e o emprego do soldado-cidadão, está se tornando obsoleta. Afinal, a propensão à guerra não é uma inclinação universal, mas fruto de um conjunto de condições que permitem o engajamento de um Estado em um conflito internacional, como resultado de uma aprendizagem: aprender a lutar.

Centeno (2002) esclarece que o Brasil e outros Estados latino-americanos não desenvolveram a capacidade ideológica ou organizacional substancial para guerrear, com objetivos políticos claros, envolvendo tempo e recursos. Suas sociedades não desenvolveram as engrenagens para as transformações logísticas e culturais exigidas pelo conflito internacional, faltando-lhes uma memória histórica exigida para a movimentação bélica, ou melhor, os repertórios culturais de guerra, até porque a maior parte dos conflitos 
políticos se deu no interior dos Estados, não entre eles. A guerra total requer uma mobilização que exige um grau de integração e de inclusão, uma organização política e administrativa capaz de modelar e direcionar a violência. Na América Latina houve pouca militarização, organização e mobilização de recursos humanos e materiais para uso potencial com fins de combate. Não se buscou uma organização com o objetivo da guerra em mente, a guerra não foi contemplada em seu cardápio estratégico em razão da existência de uma mente profissional militar não-beligerante. Os chamados patrióticos tendem a soar superficiais, assim como os apelos para os sacrifícios da própria vida em nome da pátria amada.

Segundo Bauman (200I), com a modernidade líquida da pós-modernidade, entrou em vigor uma nova configuração de guerra na qual o poder se faz de forma extraterritorial, não mais limitado pela resistência do espaço. A estratégia clássica da guerra absoluta vem sendo substituída pela estratégia indireta da guerra à distância, sobretudo em razão das inovações técnicas amparadas na informática:

A guerra para as sociedades ricas e pós-modernas será assim 'desmassificada', quer dizer, a destruição será precisa, 'sob medida' e liberada das pressões territoriais. Ela será conduzida por soldados inteligentes e regida por sistemas de comunicação em tempo real, permitindo as operações à distância, rápidas e integradas (BRASIL, 2007, p. 15).

Em resposta a essas mudanças, é provável que várias dimensões do pensamento estratégico clássico, que ainda norteiam a força naval, sobrevivam; enquanto outras, perecerão, afetando a dinâmica do dia a dia das Forças Armadas, bem como o perfil e a mentalidade do militar. Em um mundo de dimensões imprecisas e de territórios alargados, a ordem unida (treinamentos para marchar) nos quartéis estaria em dissonância com a sofisticação e os custos das manobras político-econômicas em jogo. A farda bordada com distintivos que anunciam o lugar do militar na corporação; a plaqueta que exibe o seu nome de guerra no bolso frontal da camisa; o número de corpo registrado na carteira de identidade militar são alguns dos elementos que parecem insuficientes para introduzi-lo nesse tabuleiro, onde se encontram na mesa cifras bilionárias, com dimensões globalizadas.

Mais do que sustentar a concepção iluminista de uma "identidade militar", como algo essencial que se mantém estável e intocada, admitindo novas tendências do perfil de profissional militar da atualidade, Giuliani (2006a; 2006b) propõe o entendimento de uma 
"identificação militar", tendo em vista a existência da fragmentação da identidade. Segundo Gauer (2004), as identidades seriam fragmentadas e constantemente redefinidas no mundo contemporâneo, em contraste com a concepção essencialista ou fixa de identidade produzida no período iluminista. A "identidade militar" e o "espírito militar" são concepções historicamente fabricadas e incutidas como verdades para o alcance de objetivos políticos e econômicos. Elas estavam em sintonia com o ethos guerreiro capaz de mobilizar os combatentes de modo a estarem sempre a postos, de armas em punho (ELIAS, 1997).

Os atributos do soldado-cidadão deixaram de garantir o êxito nas operações bélicas do mundo pós-moderno. Na contramão das novas tendências estratégias, os deslizes à luz do RDM e os valores preconizados no Estatuto dos Militares continuam a determinar quem será o bom e o mau militar na MB. Na realidade da caserna, os militares continuam sendo avaliados, julgados ou condenados segundo esses parâmetros. Observa-se a existência de uma lacuna entre o que está escrito e a vivência diária. Verifica-se que, nesses hiatos, a partir das "prescrições", podem surgir maiores chances de ocorrerem as "transgressões" tais como os transtornos, as falhas e as contravenções, como manifestações de um descompasso entre a letra e o cotidiano.

É preciso atentar para o fato de que, tanto os critérios profissionais preconizados, quanto os instrumentos legais disponíveis, foram igualmente produzidos, inventados, por força de contingências externas, tornando-se “tradições”. "Muitas vezes, 'tradições' que parecem ou são consideradas antigas são bastante recentes, quando não são inventadas" (HOBSBAWM, 2008, p. 9). Profissões e seus profissionais também são produções circunstanciais, assim como o que se considera importante ou irrelevante, ou o que se tem por certo ou errado. Embora eles tenham sido considerados como fundamentais no passado, acredita-se que eles possam ser repensados, até porque eles continuam a demarcar as fronteiras entre os "marinheiros dóceis" e os "marginais".

Se houve uma época em que a reprovação do uso da chibata como instrumento correcional não foi unânime, demorando alguns anos para ser banido, analogamente, os "instrumentos correcionais" da atualidade (normas, regulamentos e valores) também não costumam ser questionados. Acredita-se que a organização naval ainda seja "míope", incapaz de analisar criticamente as práticas em voga, naturalizando-as em razão dos usos e costumes. Uma "cegueira" e/ou conformismo parecem prevalecer, mantendo o status quo, em nome da "tradição". Há que se indagar se não existe uma lacuna entre o que está previsto nos regulamentos e as possibilidades concretas de sua aplicação em pessoas de 
“carne e osso". É fundamental que a organização naval procure sintonizar a realidade dos indivíduos que integram o contingente naval com as suas reais potencialidades e limitações.

\section{Referências bibliográficas}

ABREU, Luiz Eduardo de Lacerda. Meia volta volver - um estudo antropológico sobre a hierarquia militar. Revista de Antropologia, v. 4I, n.I, 1998.

ARIAS NETO, José Miguel. Em busca da cidadania: Praças da Armada Nacional I867-I9Io. Tese (Doutorado em História), Curso do Programa de Pós-Graduação em História Social, Universidade de São Paulo, 200I.

BAUMAN, Zygmunt. O mal-estar na pós-modernidade. Rio de Janeiro: Zahar, 1998. . Modernidade líquida. Rio de Janeiro, Zahar, 200 I. . Vidas desperdiçadas. Rio de Janeiro, Zahar, 2005.

BEATTIE, Peter M. Ser homem pobre, livre e honrado: a sodomia e os praças nas Forças Armadas brasileiras (I860-1930). In: CASTRO, Celso; IZECKSOHN, Vitor; KRAAY, Hendrik (Orgs.). Nova história militar brasileira. Rio de Janeiro: FGV. 2004, p. 269-299.

BRASIL. Artigos de guerra. Lisboa: Galhardo e Irmãos, I84I. . Lei $\mathrm{n}^{-} \mathbf{6} 688$, de 9 de dezembro de $\mathbf{1 9 8 0}$. Dispõe sobre o Estatuto dos Militares. Rio de Janeiro: Serviço de Documentação da Marinha. Diário Oficial da União, Título I de II de dezembro, 1980.

. Decreto $\mathrm{n}^{\mathrm{o}} 88.545$, de 26 de julho de 1983. Aprova o Regulamento Disciplinar para a Marinha e dá outras providências. Rio de Janeiro: Serviço de Documentação da Marinha, I983.

. Decreto $\mathrm{n}^{\mathrm{o}}$ 95.480 de $\mathrm{I} 3$ de dezembro de 1987. Aprova a Ordenança Geral para o Serviço da Armada. Rio de Janeiro: Serviço de Documentação da Marinha, 1987.

. Constituição da República Federativa do Brasil. Brasília: Gráfica do Senado, 1988.

. Escola de Guerra Naval EGN-304B: guia para estudos de estratégia, Rio de Janeiro: Escola de Guerra Naval, 2007.

CARVALHO, José Murilo de. Brasil: nações imaginadas. Antropolítica: Revista Contemporânea de Antropologia e Ciência Política, v.I, n. I, p. 7-36, 1995.

CASTRO, Celso. A origem social dos militares: novos dados para uma antiga discussão, Novos Estudos CEBRAP. São Paulo, n.37, p. 225-23I, 1993. 
CENTENO, Miguel Angel. Blood and debt: war and the nation-state in Latin America. University Park, PA: Pennsylvania State University Press, 2002.

COATES, Timothy J. Convicts and orphans: forced and state-sponsored colonizers in the Portuguese empire, I550-I755. Standford: Standford University Press, 200I.

COSTA, Fernando Dores. Os problemas do recrutamento militar no final do século XVIII e as questões da construção do estado e da nação, Análise Social, v.30, n.I30, p. I2I-I55, 1995.

COUTINHO, Jacinto Nelson de Miranda. O papel do novo juiz no processo penal, In: (Org.), Crítica à Teoria Geral do Direito Processual Penal. Rio de Janeiro: Renovar, 2001.

DA MATTA, Roberto. Carnavais, malandros e heróis: para uma sociologia do dilema brasileiro. $6^{\mathrm{a}}$ ed. Rio de Janeiro: Rocco, 1997.

DEJOURS, Christopher. O fator humano. $5^{\mathrm{a}}$ ed. Rio de Janeiro: FGV, 2005.

DOUGLAS, Mary. Pureza e perigo. São Paulo: Editora Perspectiva, 1966.

DUARTE, Érico Esteves. A análise crítica de Clausewitz (Kritik): o rigor epistemológico e potencial interdisciplinar. In: $2^{\circ}$ Encontro Nacional da Associação Brasileira de Defesa Nacional, Niterói, 2008.

ELIAS, Norbert. Os alemães: a luta pelo poder e a evolução do habitus nos séculos XIX e XX. Rio de Janeiro: Zahar, 1997.

ELIAS, Norbert; SCOTSON, John L. Os estabelecidos e os outsiders: sociologia das relações de poder a partir de uma pequena comunidade. Rio de Janeiro: Zahar, 2000.

FOUCAULT, Michel. Vigiar e punir: nascimento da prisão. $34^{\mathrm{a}}$ ed. Petrópolis, Rio de Janeiro: Vozes, 1975/2007.

. Microfísica do poder. Rio de Janeiro: Graal, 1979.

GAUER, Ruth. Interrogando o limite entre historicidade e identidade. In: GAUER, Ruth (Org.). A qualidade do tempo para além das aparências históricas. Rio de Janeiro: Lumen Juris, 2004 .

GIULIANI, Ricardo Henrique Alves. Processo penal militar: uma análise do ritual judiciário, disciplina e hierarquia. Dissertação (Mestrado em Ciências Criminais) Faculdade de Direito, PUCRS. Porto Alegre, 2006a.

. Ritual e Processo Penal Militar: hierarquia e disciplina na (dis)função de julgar do juiz militar. http://www.dpu.gov.br/pdf/artigos/Artigo_Juiz_Militar.pdf Acesso em o9 maio 2013, 2006b.

GREENHALGH, Juvenal Ferreira de Lima. Presigangas e calabouços ou prisões da Marinha no século XIX. Rio de Janeiro: Serviço de Documentação da Marinha, 1998. 
HOBSBAWM, Eric. Introdução: a invenção das tradições. In: HOBSBAWM, Eric; RANGER, Terence (Org.). A invenção das tradições. Rio de Janeiro: Paz e Terra, 2008, p. 9-23. HALPERN, Elizabeth Espindola; LEITE, Ligia Maria Costa. The construction of the alcoholic habitus and alcohol consumption in the workplace among military patients of Brazilian Navy. Cadernos de Saúde Coletiva, v. I9, n. 3, p. 356-365, jul. 2011 .

- Decifrando os significados dos comportamentos etílicos navais de pacientes militares. Boletim de Psicologia, v. 6I, n. I35, p. I77-I9I, jul. 20 IIb.

. A farda "siri cozido" e a "branquinha": narrativas de vida de um paciente militar alcoolista. Cadernos de Psicologia Social do Trabalho, v. I5, n. I, p. 65-80, 2012.

A interseção entre os trabalhos marinheiros e o alcoolismo. Revista Psicologia: Organizações e Trabalho, v. I3, n. 2, p. III-I26, maio-ago. 2013 a.

. Oportunidades de beber a bordo: características do labor naval. Physis: Revista de Saúde Coletiva, v. 23, n. 4, p. 1277-1296, 2013 b.

- Etilismo na jornada laboral: peculiaridades da vida naval. Revista Saúde e Sociedade, v. 23, n. I, p. I3I-I45. 20I4a.

Examining the role of Brazilian Navy before alcohol intake in the workplace Psychology, v. 5, n. 2, p. IO4-IO8, 2014 b.

. Tradições e punições: a cachaça do marujo e o uísque do comandante. Dilemas: Revista de Estudos de Conflito e Controle social, v. 8, n. 2, p. 357-388, abr-maio-jun. 20I4c.

. Marinha do Brasil: uma trajetória do enfardamento. Antíteses, v. 7, n. I3, p. 158-I83, jan/jun, 20I4d.

O "uniforme" e o "copo": entrecruzamentos (des)necessários. Antropolítica: Revista Contemporânea de Antropologia e Ciência Política, n. 36, p. I79-209, Isem. 2014e.

HUNTINGTON, Samuel P. 1997. O soldado e o estado: teoria e política das relações entre civis e militares. Rio de Janeiro: Bibliex, 547p.

IZECKSOHN, Vitor. Recrutamento militar no Rio de Janeiro durante a Guerra do Paraguai, In: CASTRO, Celso; IZECKSOHN, Vitor; KRAAY, Hendrik (Orgs.). Nova história militar brasileira. Rio de Janeiro: FGV. 2004, p. I79-207.

LEIRNER, Piero de Camargo. Meia-volta volver: um estudo antropológico sobre a hierarquia militar. Rio de Janeiro: Editora FGV, 1997.

LUZ, Madel Therezinha. As instituições médicas no Brasil: instituição e estratégia de hegemonia. Rio de Janeiro: Graal, 1979.

Natural, racional, social: razão médica e racionalidade científica moderna. Rio de Janeiro: Campus, I988. 
MARTINS, Helio Leoncio. João Cândido e a Revolta de I9Io. Navigator - Subsídios para a História Marítima do Brasil. Rio de Janeiro: Serviço de Documentação da Marinha, v.I, n.I, p. $76-84,2005$.

McBETH, Michael G. The Brazilian recruit during the First Empire: slave or soldier? In: ALDEN, Dauril; DEAN, Warren. (Eds.). Essays concerning the socioeconomic history of Brazil and Portuguese India. Gainesville, FL: The University Presses of Florida. 1977, p. 7I-86.

MENDES, Fábio Faria. A economia moral do recrutamento militar no Império brasileiro, Revista Brasileira de Ciências Sociais, v.I3, n.38, 1998.

Encargos, privilégios e direitos: o recrutamento militar no Brasil nos séculos XVIII e XIX. In: CASTRO, Celso; IZECKSOHN, Vitor; KRAAY, Hendrik (Orgs.). Nova história militar brasileira. Rio de Janeiro: FGV, 2004, p. III-I37.

NASCIMENTO, Álvaro Pereira do. A ressaca da marujada: recrutamento e disciplina na Armada Imperial, I880-I9I9. Rio de Janeiro: Arquivo Nacional, 200I.

PALMER, R. R. Frederico, o grande, Guibert, Bülow: da guerra dinástica à guerra nacional. In: PARET, Peter. (Org.). Construtores da estratégia moderna: de Maquiavel à era nuclear. v.I. Rio de Janeiro: Biblioteca do Exército Editora, 200I, p. 27-53.

RODRIGUES, Flávio Luiz. Vozes do mar: o movimento dos marinheiros e o golpe de 64. São Paulo: Cortez, 2004.

ROTHENBERG, Gunther. E. Mauricio de Nassau, Gustavo Adolfo, Raimondo Montecuccoli: 'Revolução Militar' do século XVII. In: PARET, Peter (Org.). Construtores da estratégia moderna: de Maquiavel à era nuclear. v.I. Rio de Janeiro: Biblioteca do Exército Editora, 200I, p. 55-96.

SCHAUMBURG-LIPPE, W. (CONDE de). Regulamento para o exercício e disciplina dos regimentos de infantaria dos exércitos de Sua Majestade Fidelíssima. Lisboa: Régia Oficina, I794. TILLY, Charles. How war made states and vice-versa. New York: New School for Social Research, 1987.

YOUNG, Jock. A sociedade excludente: exclusão social, criminalidade e diferença na modernidade recente. Rio de Janeiro: Revan, Instituto Carioca de Criminologia, 2002. 